\title{
Functioning portacath with subclavian vein thrombosis: When to remove $\&$ when to leave?
}

\author{
Hisham Mostafa, ${ }^{a}$ MD; Osama Lotfy, ${ }^{a}$ MD, MRCS; Amr Sakr, ${ }^{b} M D$; \\ Ahmed Haroun, $c$ MD; Khaled Alkaffas, ${ }^{d} M D$
}

\author{
a) Department of General Surgery, Cairo University, Cairo, Egypt. \\ b) Department of Medical Oncology, Cairo University, Cairo, Egypt. \\ c) Department of Internal Medicine, Cairo University, Cairo, Egypt. \\ d) Department of Radio-diagnosis, Cairo University, Cairo, Egypt.
}

\begin{abstract}
Background: The use of portacath became a commonplace in anticancer treatment. However infections and deep venous thrombosis are two serious complications that might be encountered. The mere evidence of infection spells immediate catheter removal, whereas the situation is totally different with deep venous thrombosis and represents a matter of debate.

Aim of the study: This study was designed to address the issue of portacath related subclavian vein thrombosis to clarify the pros \& cons of either catheter removal or leaving to justify when to adopt each plan.

Patients and methods: Twenty-eight patients having portacath with subclavian vein thrombosis were randomly divided between 2 groups (14 patients each) according to the management plan. Group A were subjected to medical treatment without catheter removal and group $B$ were subjected to medical treatment, catheter removal and insertion of a new one as necessary in another vascular bed. Both groups were compared regarding the baseline relevant data and the treatment outcome.

Results: There was no statistically significant difference between both groups regarding the duration till start of clinical improvement ( $P$ value 0.682), maximum clinical improvement $(P$ value 0.445$)$, and start of recanalization ( $P$ value 0.218$)$. However, the duration until complete recanalization was significantly shorter in the catheter removal group $B$ (P value 0.05). Although in the catheter leaving group A the hospital stay was significantly longer ( $P$ value 0.001), yet, the overall cost was significantly less ( $P$ value 0.05). Re-thrombosis, postphlebitic limb, pulmonary embolism were not encountered in either groups.

Conclusion: In addition to the cost and the extra-procedure, removal of a still needed well placed functioning catheter with subsequent insertion of another one in the contra-lateral side has no clinical privilege. It also carries the same risk of subclavian vein re-thrombosis in the old side and the chance of thrombosis in the new side.
\end{abstract}

Key words: Portacath, removal, subclavian, vein \& thrombosis.

\section{Introduction:}

The use of indwelling totally implantable central venous catheters (portacath) became a commonplace in anticancer treatment, and inspite of the great value of their use, four types of possible complications were defined: mechanical, thrombotic, mal-functioning and infections. ${ }^{1}$ By far, the most two serious are infections and deep venous thrombosis that mandate an energetic wise decision. While the mere evidence of infection spells immediate catheter removal, the situation is totally different with deep venous thrombosis and represents a matter of debate in its management.

Thrombosis is a common complication in patients with malignant disease, resulting from tumor liberation of pro-coagulants with subsequent activation of intravascular coagulation factors. Cancer therapies as operations, chemotherapy, and the use of portacath further heighten the risk of thrombosis. ${ }^{2}$ 
This study was designed to address the issue of portacath related subclavian vein thrombosis to clarify the pros \& cons of either catheter removal or leaving to justify when to adopt each plan.

\section{Patients and methods:}

Twenty-eight patients on chemotherapy with functioning portacath and related cubclavian vein thrombosis were included in this study. These patients came from screening and follow up of asymptomatic patients attending oncology clinics to have their chemotherapy cycles (11 patients), and also from patients referred with symptoms and signs or documentations for subclavian vein thrombosis (17 patients). Exclusion criteria included: patients with non-functioning portacath, mal-directed or high sited tip in the subclavian vein and or infection.

All the study patients were evaluated by history taking, clinical examination and assessment using color-coded duplex scanning (CCDS) by advanced high resolution B-mode and color doppler sonography equipment and a 5-7.5 MHz linear-array transducer. The CCDS examination technique included imaging of the internal jugular vein in a transverse view along its course adjacent to the common carotid artery in the neck. The subclavian and innominate veins were evaluated from a supraclavicular approach with the transducer aimed inferiorly and slightly medially. The criteria used to diagnose venous thrombosis by CCDS included the absence of spontaneous flow and loss of cardiac and respiratory phasicity distal to the thrombosed vein Figure(1), the visualization of intraluminal thrombi surrounding the portacath Figure(2) and/or the inability to compress the vein. ${ }^{3}$ The duplex scan played also an important role in follow up till re-canalization Figures(3,4). Plain chest $\mathrm{X}$-ray was done for all patients to verify the site of the catheter tip Figures $(\mathbf{5 , 6})$. CT of the chest was done selectively in suspected mediastinal syndrome.

The 28 patients were studied regarding the following items: 1 . patient related parameters: age, sex, past history of DVT and anti-thrombin III, protein $\mathrm{C}$, protein $\mathrm{S}$, anti-phospholipid, fibrinogen and platelets abnormalities, 2. disease related parameters: type of malignancy and type and duration of chemotherapy, and 3. catheter related parameters: site of the catheter tip, side of the catheter and duration of the catheter application.

These patients were randomly divided between 2 groups of management (A \& B, 14 patients each) and an informed written consent was obtained from all of them. Group A were subjected to medical treatment without catheter removal (the catheter was still needed in all of them) and Group B were subjected to medical treatment, catheter removal and insertion of new one as necessary in another vascular bed. Medical treatment included anticoagulant therapy, rest and elevation of the affected extremity. Weight-adjusted twice daily subcutaneous low molecular weight heparin and warfarin were initiated immediately. The low molecular weight heparin was used for 5 to 7 days until the start of action of warfarin when the INR became around 2 on 2 consecutive days. Warfarin therapy was continued for 3-6 months.

Follow up of both groups compared the duration until the start of and maximum clinical improvement, the duration until the start of and the complete recanalization, the duration of hospital stay, the cost and the complications. The data was collected, presented, and statistically analyzed. 


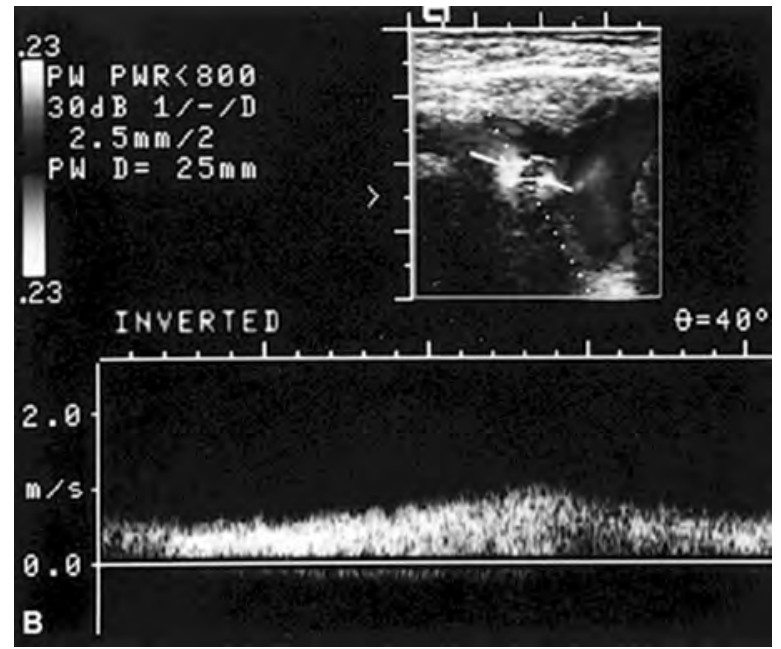

Figure (1): Pulsed doppler from the subclavian vein distal to thrombosis showing continuous flow with loss of respiratory and cardiac phasicity.

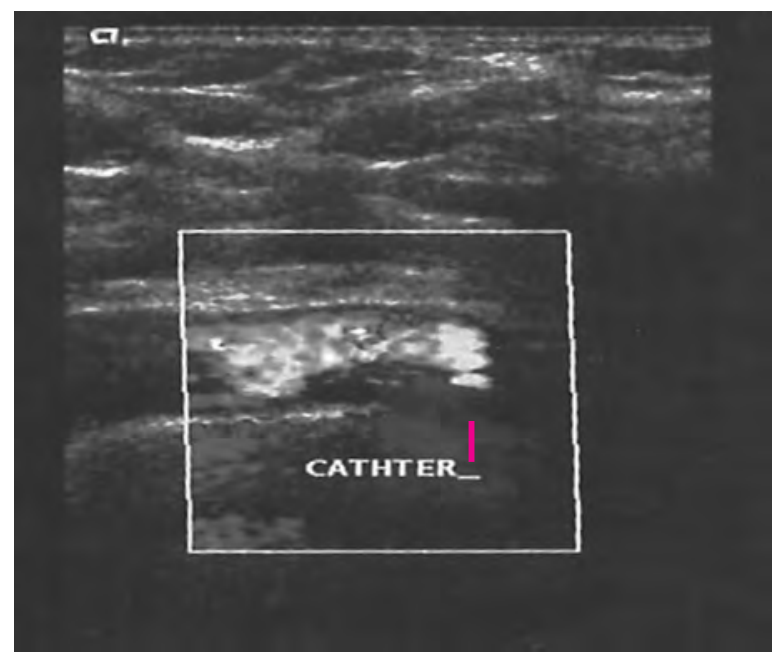

Figure (3): Duplex image of the subclavian vein thrombosis showing starting recanalization, the portacath is seen within (arrow).

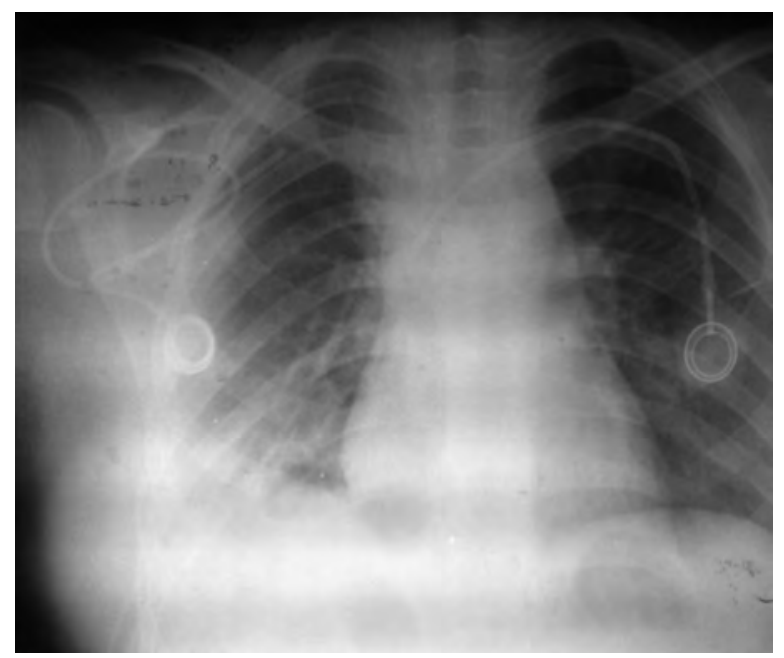

Figure (5): Chest X-ray with the right port tip in the right subclavian vein and the recently applied left one tip high in the SVC.

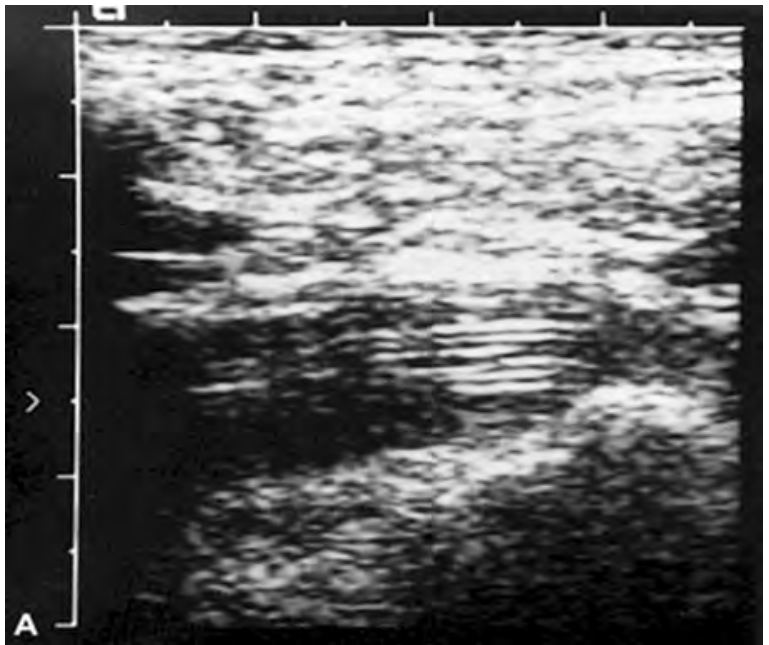

Figure (2): Longitudinal gray-scale image of the proximal subclavian vein \& a portacath within surrounded by echogenic thrombosis obstructing the lumen.

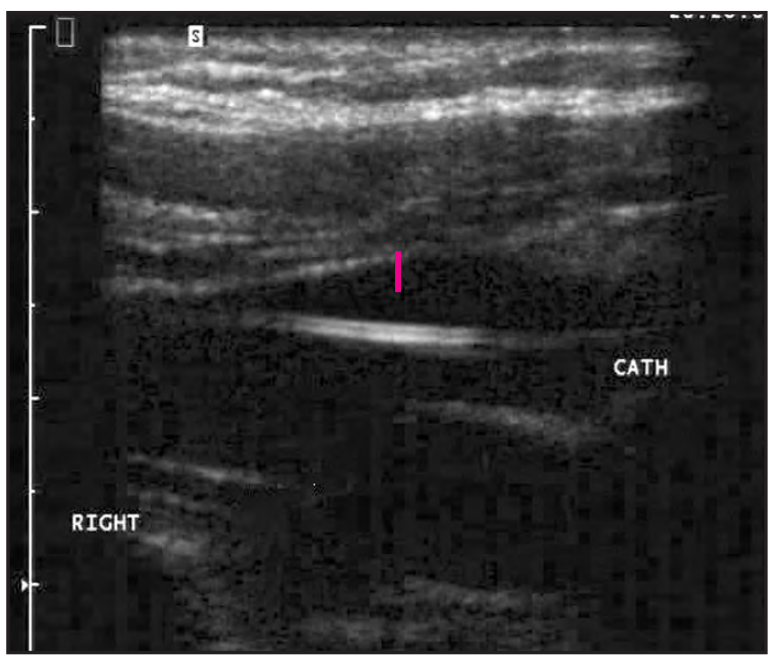

Figure (4): Portacath (arrow) in the right subclavian vein after complete recanalization.

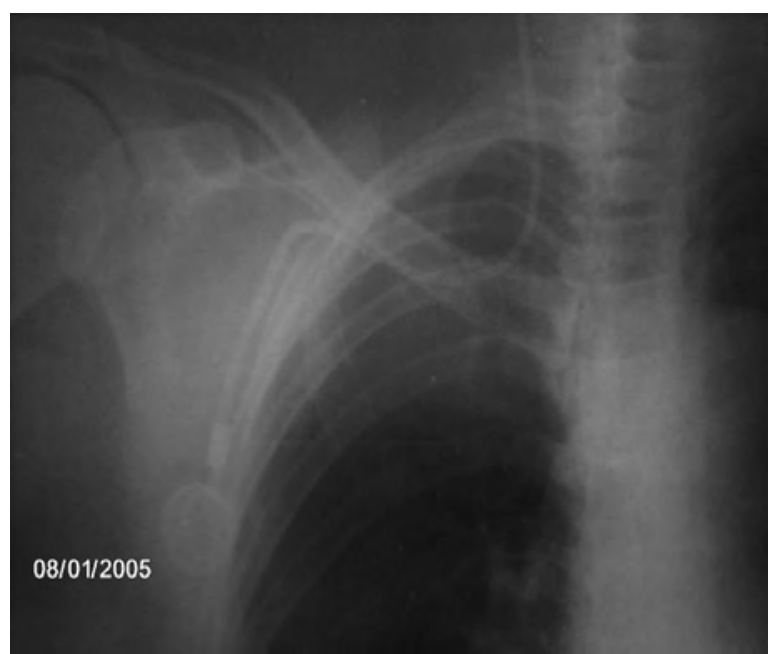

Figure (6): Chest X-ray with mal-directed subclavian catheter to the epsi-lateral internal jugular vein. 


\section{Results:}

The demographic and clinical data in both groups are presented in Table(1).

Table (1): Demographic and clinical data of both groups.

\begin{tabular}{|c|c|c|c|}
\hline & $\begin{array}{c}\text { Group A } \\
\text { (catheter leaving) }\end{array}$ & $\begin{array}{c}\text { Group B } \\
\text { (catheter removal) }\end{array}$ & P-value \\
\hline Age (year)* & $53.3 \pm 16.2$ & $52.7 \pm 18.1$ & 0.624 \\
\hline Sex & 6 males and 8 females & 7 males and 7 females & - \\
\hline $\begin{array}{c}\text { Time from catheter application } \\
\text { to thrombosis in symptomatic } \\
\text { patients* }\end{array}$ & $102 \pm 87$ days & $114 \pm 65$ days & 0.072 \\
\hline $\begin{array}{c}\text { Past history of DVT } \\
\text { Duration of chemotherapy* }\end{array}$ & $67 \pm 45$ days & None & - \\
\hline Total number of patients & (14 patients) & $(14$ patients) & 0.112 \\
\hline
\end{tabular}

*Data are mean $\pm S D$.

Most of those who developed subclavian vein thrombosis in the studied patients had their catheter tip high up in the superior vena cava or innominate vein (17/28 patients $60.7 \%)$. Subclavian vein thrombosis was more common on the left side $(21 / 28$ patients $75 \%)$.

Six patients in group A and 5 patients in group B were on FAC regimen (5-flourouracil, adriamycin, and cyclophosphamide) as an adjuvant treatment for breast cancer. Six patients in group A and 6 patients in group B were on 5-flourouracil, and leucoporin regimen for treatment of colorectal malignancy. Two patients in group A and 3 patients in group B were on cisplatinum, and gimcitapen regimen for treatment of bronchogenic carcinoma.

The clinical presentations of the symptomatic patients and the thrombotic profile of all patients are shown in Tables $(2,3)$.

Table (2): Clinical presentation in symptomatic patients in group A and B.

\begin{tabular}{|l|c|c|}
\hline & Group A (cath leaving) & Group B (cath removal) \\
\hline Limb swelling. & $6(100 \%)$ & $7(100 \%)$ \\
\hline Upper limb \& chest pain. & $5(83 \%)$ & $5(71 \%)$ \\
\hline Numbness of the extremity, & $4(67 \%)$ & $5(71 \%)$ \\
\hline Cyanosis of the extremity, & $2(33 \%)$ & $3(43 \%)$ \\
\hline Total number & 6 & 7 \\
\hline
\end{tabular}

Table (3): Comparison of thrombotic profile between group A and B.

\begin{tabular}{|l|c|c|c|}
\hline & $\begin{array}{c}\text { Group A } \\
\text { catheter leaving }\end{array}$ & $\begin{array}{c}\text { Group B } \\
\text { catheter removal }\end{array}$ & P value \\
\hline AT III\% * (anti thrombin III) & $68 \pm 19$ & $74 \pm 12$ & 0.172 \\
\hline Protein C \%* & $97 \pm 7$ & $88 \pm 10$ & 0.226 \\
\hline Protein S\%* & $89 \pm 5$ & $84 \pm 9$ & 0.455 \\
\hline Antiphospholipid antibodies & Negative & Negative & - \\
\hline Fibrinogen level (mg/dL) & $364 \pm 53$ & $336 \pm 64$ & 0.091 \\
\hline Platelet count $\left(\mathbf{m m m}^{3)}\right)$ & $440000 \pm 45000$ & $390000 \pm 80000$ & 0.102 \\
\hline
\end{tabular}

Data are mean $\pm S D$.

* Assays for AT III, Protein C, and Protein $S$ were functional assays. 
Patients in group A and B were matching regarding the before mentioned parameters.
The data comparing the treatment outcomes in both groups are presented in Table(4).

Table (4): Outcome of treatment in group A and B.

\begin{tabular}{|l|c|c|c|}
\hline & $\begin{array}{c}\text { Group A } \\
\text { Catheter leaving }\end{array}$ & $\begin{array}{c}\text { Group B } \\
\text { Catheter removal }\end{array}$ & P value \\
\hline Duration till start of clinical improvement $*$ & $5 \pm 2$ days & $4 \pm 1$ days & 0.682 \\
\hline Duration till maximum clinical improvement $*$ & $24 \pm 5$ days & $23 \pm 5$ days & 0.445 \\
\hline Duration till start of recanalization & $23 \pm 3$ days & $24 \pm 3$ days & 0.218 \\
\hline Duration of complete recanalization & $62 \pm 17$ days & $55 \pm 13$ days & 0.05 \\
\hline Duration of hospital stay $*$ & $8 \pm 2$ days & $4 \pm 3$ days & 0.001 \\
\hline Cost \# & LE 2275 (average) & LE 3400 (average) & 0.05 \\
\hline Re-thrombosis & None & None & - \\
\hline Post-phlebitic limb & None & None & - \\
\hline Pulmonary embolism & None & None & - \\
\hline
\end{tabular}

* Only in symptomatic patients in both groups.

\# Cost included; the cost of anticoagulant therapy and hospital stay in both groups, and the cost of catheter removal and new catheter application in group $B$.

There was no statistically significant difference between both groups regarding the durations till start of clinical improvement, maximum clinical improvement, and start of recanalization. However, the duration until complete recanalization was significantly shorter in catheter removal group B. In catheter leaving group A, although the hospital stay was longer, yet the overall cost was significantly less. Re-thrombosis, postphlebitic limb and pulmonary embolism were not encountered in either group.

Patient satisfaction was evaluated according to the following items:

1. Fear from complication (nonimprovement, re-thrombosis, pulmonary embolism, and post-phlebitic limb), 2. duration of hospital stay, 3. discomfort from further intervention and 4. cost. Items 1 and 2 were more pronounced in catheter leaving group $\mathrm{A}$ and items 3 and 4 were more pronounced in catheter removal group B.

\section{Discussion:}

Portacath induced subclavian vein thrombosis may be inevitable complication in a minority of patients, but this should not influence the port usability with respect to its advantages in the majority of the patients. The pathogenesis of catheter related subclavian vein thrombosis is multi-factorial. Vessel injury caused by the insertion procedure, venous stasis caused by the indwelling catheter, chemotherapy administration and cancerrelated hyper-coagulability contribute to its development. Some types of malignancy may be associated with an increased rate of catheter related venous thrombosis. Anderson et al 1989 reported that $45 \%$ of patients with adenocarcinoma of the lung developed symptomatic central venous catheter related thrombosis, in comparison to $9 \%$ in those with head and neck cancer. ${ }^{4}$ The type and regimen of chemotherapy can also be a contributing factor for venous thrombo-embolic events. ${ }^{5}$ However, Brown et al 1997 found no difference in thrombotic complications for patients receiving different regimens of chemotherapy (bolus versus infusion regimens, and homebased versus hospital-based chemotherapy administration). ${ }^{6}$

The catheter tip position in the vascular system is a major determinate for related thrombosis. More thrombosis is seen when the catheter tip is placed high in the superior vena cava than when the catheter tip is placed low in the superior vena cava. ${ }^{7-11}$ The results of 
the current study support this postulation. A possible explanation is the increased chance of damage to the blood vessel and the less dilution of the chemotherapeutic when the catheter tip is in the higher position. In the current and other studies, it was found that subclavian vein thrombosis was more common with left sided than right sided inserted catheters. ${ }^{12-14}$

Assessment of the coagulation profile was done to verify if the catheter related subclavian vein thrombosis in either group was due to pre-existing primary or secondary blood disease that may bias the results of comparison. Fibrinogen level and platelet count were mildly elevated in both groups without a statistically significant difference ( $\mathrm{P}$ value 0.063 ) between the 2 groups. Protein $\mathrm{C}$, protein $\mathrm{S}$ levels were normal in both groups and all cases were negative for anti-phospholipid antibodies. Thrombocytosis is a well-recognized accompaniment of malignancy. It is unclear, whether these changes are secondary to malignancy or due to initial earlier changes in the coagulation system that "activate" platelets and make them "hyperaggregable.". 15 A high platelet count at the time of catheter insertion seems to be correlated with the rate of thrombotic complications in cancer patients. Haire et al reported a lower risk of catheter related DVT in cancer patients with a low platelet count. ${ }^{16}$

There is no firm consensus on the therapy for catheter-related thrombosis. Anticoagulation is the mainstay of therapy with the premise of preventing clot propagation and allowing for collateral formation. ${ }^{17}$ The handling of the catheter itself varied in the literature. The aim of this randomized trial was to study the clinical course and outcome when the catheter was left (group A) or explanted (group B). The start of clinical improvement, and the duration of maximum clinical response was similar in both groups as well as the start of recanalization. However, the duration until complete recanalization was significantly shorter in group B who were subjected to catheter removal.

The outcome of this study can state that removal of a functioning non-infected portacath in cases of subclavian vein thrombosis is not mandatory as the clinical course regarding improvement was similar whether the catheter was left or removed. However, leaving the catheter is still controversial ${ }^{18-20}$ and should be left for the discretion of the attending physician depending on the duration needed to administer additional chemotherapy.

It is worthy to know that what made the controversy in catheter management is that the pros of removal are cons for leaving and vice versa. The current study proved that catheter removal carries a shorter duration until complete recanalization, but this was not apparently reflected on the clinical outcome. The duration of hospital stay was also shorter with catheter removal, but the overall cost was higher because of the additional cost of catheter removal and insertion of a new one in the contra-lateral side. Removal of the catheter does also alleviate the anxiety and fear of leaving a catheter in a thrombosed vein, but usually the patient is not aware that catheter insertion on the contra-lateral side may carry the same risk in addition to the chance of rethrombosis in the old site.

\section{Conclusion:}

Unless the tip is mal-directed or high in the subclavian vein, removal of the catheter in patients with port associated subclavian vein thrombosis is not a guarantee against thromboembolism and has no significant impact on the clinical course. In addition to the cost and extra-procedure, removal of a still needed catheter with subsequent insertion of another one in the contra-lateral side, carries the same chance of subclavian vein thrombosis in the new side and re-thrombosis in the old side. Then, why to rush for removal of a well placed still needed functioning portacath?

\section{References:}

1- Fratino G, Molinari AC, Parodi S, Longo S, Saracco P, Castagnola E, Haupt R: Central venous catheter-related complications in children with oncological/hematological diseases: An observational study of 418 devices. Ann Oncol 2005; 16(4): 648-645.

2- Kakkar AK, Williamson RC: Thromboprophylaxis in the cancer patient. Haemostasis 1998; 28(Suppl 3): 61-65. 
3- Richlie DG: Noninvasive imaging of the lower extremity for deep venous thrombosis. J Gen Intern Med 1993; 8: 271-277.

4- Anderson AJ, Krasnow SH, Boyer MW: Thrombosis: The major Hickman catheter complication in patients with solid tumor. Chest 1989; 95: 71-75.

5- Koksoy C, Kuzu A, Erden I, et al: The risk factors in central venous catheter-related thrombosis. Aust N Z J Surg 1995; 65: 796798.

6- Brown DF, Muirhead MJ, Travis PM, et al: Mode of chemotherapy does not affect complications with an implantable venous access device. Cancer 1997; 80: 966-972.

7- Schwarz RE, Coit DG, Groeger JS: Transcutaneously tunneled central venous lines in cancer patients: An analysis of device-related morbidity factors based on prospective data collection. Ann Surg Oncol 2000; 7: 441-449.

8- Craft PS, May J, Dorigo A, Hickman catheters: Left-sided insertion, male gender, and obesity are associated with an increased risk of complications. Aust $N Z \mathrm{~J} \mathrm{Med}$ 1996; 26: 33-39.

9- Eastridge BJ, Lefor AT: Complications of indwelling venous access devices in cancer patients. J Clin Oncol 1995; 13: 233-238.

10 -Nightingale CE, Norman A, Cunningham D: A prospective analysis of 949 long-term central venous access catheters for ambulatory chemotherapy in patients with gastrointestinal malignancy. Eur J Cancer 1997; 33: 398-403.

11-Stanislav GV, Fitzgibbons RJ, Bailey RT: Reliability of implantable central venous access devices in patients with cancer. Arch Surg 1987; 122: 1280-1283.

12-Gould JR, Carloss HW, Skinner WL: Groshong catheter-associated subclavian venous thrombosis. Am J Med 1993; 95: 419-423.
13-Carr KM, Rabinowitz I: Physician compliance with warfarin prophylaxis for central venous catheters in patients with solid tumors. J Clin Oncol 2000; 18: 36653667.

14-Brown-mith JK, Stoner MH, Barley ZA: Tunneled catheter thrombosis: Factors related to incidence. Oncol Nurs Forum 1990; 17: 543-549.

15-Bick RL: Alterations of hemostasis in malignancy. In: Disorders of thrombosis and hemostasis: Clinical and laboratory practice. Chicago: ASCP Press (Publisher); 1992; p.239.

16-Haire WD, Leiberman RP, Edney J, et al: Hickman catheter-induced thoracic vein thrombosis: Frequency and long-term sequelae in patients receiving high-dose chemotherapy and marrow transplantation. Cancer 1990; 66: 900-908.

17-Reed JD, Harman JT, Harris V: Regional fibrinolytic therapy for iatrogenic subclavian vein thrombosis. Seminars in Interventional Radiology 1992; 9: 183189.

18-Kock HJ, Pietsch M, Krause U, et al: Implantable vascular access systems: Experience in 1500 patients with totally implanted central venous port systems. World J Surg 1998; 2: 12-16.

19-Kröger K, Grütter R, Rudofsky G, Fink H, Niebel W: Follow-up after portacath induced thrombosis. Journal of Clinical Oncology 2002; 20(10): 2605-2606.

20-Poorter RL, Lauw FN, Bemelman WA, et al: Complications of an implantable venous access device (Portacath) during intermittent continuos infusion of chemotherapy. Eur J Cancer 1996; 32: 2262-2266. 